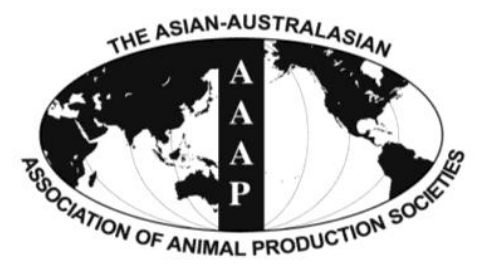

Asian-Aust. J. Anim. Sci.

Vol. 26, No. 2 : 260-265 February 2013

http://dx.doi.org/10.5713/ajas.2012.12487

www.ajas.info

pISSN $1011-2367$ elSSN 1976-5517

\title{
Effects of Dietary Persimmon Peel and its Ethanol Extract on the Production Performance and Liver Lipids in the Late Stage of Egg Production in Laying Hens
}

\author{
S. T. Oh, L. Zheng, Y. K. Shin, B. K. An and C. W. Kang* \\ College of Animal Bioscience and Technology, Konkuk University, \\ 1 Hwayang-dong, Gwangjin-gu, Seoul 143-701, Korea
}

\begin{abstract}
The purpose of this study was to investigate the dietary effects of persimmon peel (PP) and PP ethanol extract (PPE) on egg production, egg quality, and liver lipids in the late stage of egg production in laying hens. One hundred and twenty 50-wk-old HyLine Brown layers $(n=120)$ were fed different diets. Four replicate groups of 6 hens each were randomly assigned to 5 dietary treatments. The 5 dietary treatments were as follows: i) CON, basal diet; ii) PP $0.15, \mathrm{CON}+0.15 \% \mathrm{PP}(0.035 \%$ tannin); iii) PP 0.5 , CON $+0.5 \%$ PP ( $0.117 \%$ tannin); iv) PPE 0.075, CON+0.075\% PPE ( $0.03 \%$ tannin); and v) PPE 0.25, CON+0.25\% PPE ( $0.11 \%$ tannin). The total tannin concentration of PPE was higher $(\mathrm{p}<0.05)$ than that of PP. Egg production in the PP 0.5 group was higher than in the other groups. Egg production and mass of hens in the PPE 0.25 group showed a greater decrease than that in the other groups $(\mathrm{p}<0.05$ ). Eggshell color in the PP 0.15, PP 0.5, and PPE 0.075 groups was lighter than that of the control group ( $<<0.05$ ). The Haugh unit for the groups that were fed PP and PPE were significantly higher than that in the other groups after $7 \mathrm{~d}$ of storage $(\mathrm{p}<0.05)$. Therefore, PP seems an effective feed additive for improving the production performance and egg quality in late stage laying hens. (Key Words: Persimmon Peel, Persimmon Peel Ethanol Extract, Laying Hen, Liver Lipid, Egg Quality)
\end{abstract}

\section{INTRODUCTION}

Persimmon (Diospyros kaki L.) is widely cultivated in Korea, Japan, and China. It contains many bioactive compounds, such as sugars, vitamins, flavonoids, tannins, terpenoids, steroids, naphthoquinones, dietary fiber, carotenoids, minerals, amino acids, and lipids (Gross, 1987; Mallavadhani et al., 1998). Generally, persimmon is divided into 2 types: sweet and astringent. The astringent persimmon is strongly astringent when small and immature. It is rich in water-soluble tannin that generates the astringent taste and, therefore, inedible even when fully colored (Taira, 1996; Parajuli et al., 2007). To remove the astringent taste, the persimmon is dried in open air after peeling. During the drying process, the water-soluble persimmon tannin forms a cross-link by condensation reaction between its hydroxyl groups, thereby, making it water insoluble and diminishing the astringent taste (Parajuli et al., 2007). Thus, a good amount of persimmon

\footnotetext{
* Corresponding Author: C. W. Kang. Tel: +82-2-450-3669, Fax: +82-2-452-9946, E-mail: kkucwkang@empal.com Submitted Sept. 10, 2012; Accepted Oct. 31, 2012; Revised Nov. 19, 2012
}

peel (PP) is wasted in countries where production is high.

Tannins in plants and fruits generally serve as antioxidant and anti-pathogenic agents (Amarowicz et al., 2000; Gorinstein et al., 2000; Gedir et al., 2005). However, high concentrations of tannin in animal feed may decrease its nutrient values (Armanious et al., 1973; Ortiz et al., 1994). It has been shown that a high level of tannin (up to $2 \%$ ) decreases egg production and quality when supplemented in diet (Potter et al., 1967; Fry et al., 1972)

Sweet-type persimmon, in particular, contains a tannin level ranging from $3 \%$ when immature to $0 \%$ at harvest time (Taira, 1996). The PP has higher concentration of polyphenols, fiber, and minerals than in the whole fruit and pulp (Gorinstein et al., 2001). Several studies on PP have been conducted to investigate its bioactive value (Gorinstein et al., 1998; Gorinstein et al., 2001). The PP ethanol extract (PPE) plays a role in multidrug resistance reversal activity because of the presence of carotenoids, flavonoids, and other functional components (Kawase et al., 2003). Furthermore, PP polyphenol exhibits inhibitory activities on high glucose-induced oxidative stress (Yokozawa et al., 2002). 
To our knowledge, there are no other studies describing the dietary effects of PP and its tannin extract in laying hens. In the present study, we investigated the dietary effects of PP and PPE on the production performance, egg quality, and liver lipids in laying hens.

\section{MATERIALS AND METHODS}

\section{Animals and diets}

One hundred and twenty 50-wk-old Hy-Line Brown hens were used in this study. Four replicate groups of 6 hens each were randomly assigned to 5 dietary treatments (3 adjacent cages with 2 hens; cage dimensions: $36 \times 40 \times 42$ $\mathrm{cm})$. The birds were allowed a 1-wk adaptation period before initiating the experiment. A corn-soybean mealbased diet (Table 1) was formulated to meet or exceed the nutrient recommendations of the NRC (1994).

The PP was collected from factories processing cured persimmon. The collected samples were dried for $1 \mathrm{wk}$ at room temperature and were further dried for another $1 \mathrm{wk}$ in airflow (below $40^{\circ} \mathrm{C}$ ). The dried PP was ground and stored until further use. The PPE was prepared according to the method by Ahn et al. (2002) with a slight modification. We extracted $100 \mathrm{~g}$ ground PP samples using $300 \mathrm{ml}$ of $70 \%$ ethanol. The mixture was filtered and the filtrate was centrifuged for $20 \mathrm{~min}$ at 3,000 rpm. The supernatant was concentrated by evaporation at $40^{\circ} \mathrm{C}$ and then freeze-dried. Total tannin concentrations of PP and PPE were determined according to the method by AOAC (1995), and the contents were $0.235 \pm 0.02 \%$ and $0.457 \pm 0.21 \%$, respectively $(n=4)$. The dietary treatments were as follows: i) $\mathrm{CON}$, basal diet; ii) PP $0.15, \mathrm{CON}+0.15 \% \mathrm{PP}(0.035 \%$ tannin $)$; iii) PP 0.5 , $\mathrm{CON}+0.5 \%$ PP $(0.117 \%$ tannin); iv) PPE $0.075, \mathrm{CON}+$ $0.075 \%$ PPE $(0.034 \%$ tannin); and v) PPE $0.25, \mathrm{CON}+$ $0.25 \%$ PPE ( $0.114 \%$ tannin). The hens were provided with feed and water ad libitum. A room temperature of $21 \pm 3^{\circ} \mathrm{C}$ and a photoperiod of 16-h light and 8-h dark were maintained throughout the experimental period.

The feeding period lasted for 6 wks. All experimental procedures were approved by the Institutional Animal Care and Use Committee of Konkuk University.

\section{Sampling and measurements}

Feed intake $(\mathrm{g} / \mathrm{hen} / \mathrm{d})$ was recorded weekly for each

Table 1. Formula and chemical composition of the experimental diet

\begin{tabular}{|c|c|c|c|c|c|}
\hline \multirow{2}{*}{ Ingredients (\%) } & \multicolumn{5}{|c|}{ Treatment $^{1}$} \\
\hline & $\mathrm{CON}$ & PP 0.15 & PP 0.5 & PPE 0.075 & PPE 0.25 \\
\hline Corn & 62.58 & 62.43 & 62.08 & 61.83 & 62.33 \\
\hline Wheat & 3.00 & 3.00 & 3.00 & 3.00 & 3.00 \\
\hline Lupine seed & 4.00 & 4.00 & 4.00 & 4.00 & 4.00 \\
\hline Soybean meal & 13.96 & 13.96 & 13.96 & 13.96 & 13.96 \\
\hline Rapeseed meal & 2.00 & 2.00 & 2.00 & 2.00 & 2.00 \\
\hline Meat meal & 3.00 & 3.00 & 3.00 & 3.00 & 3.00 \\
\hline Limestone & 9.51 & 9.51 & 9.51 & 9.51 & 9.51 \\
\hline Dicalcium phosphate & 0.55 & 0.55 & 0.55 & 0.55 & 0.55 \\
\hline Salt & 0.25 & 0.25 & 0.25 & 0.25 & 0.25 \\
\hline Tallow & 0.80 & 0.80 & 0.80 & 0.80 & 0.80 \\
\hline Choline-chloride (50\%) & 0.08 & 0.08 & 0.08 & 0.08 & 0.08 \\
\hline DL-methionine & 0.07 & 0.07 & 0.07 & 0.07 & 0.07 \\
\hline Mineral $\operatorname{mix}^{2}$ & 0.10 & 0.10 & 0.10 & 0.10 & 0.10 \\
\hline Vitamin $\operatorname{mix}^{3}$ & 0.10 & 0.10 & 0.10 & 0.10 & 0.10 \\
\hline Persimmon peel powder & - & 0.15 & 0.50 & - & - \\
\hline Soluble tannin extract & - & - & - & 0.075 & 0.25 \\
\hline \multicolumn{6}{|c|}{ Calculated analysis of basal diet } \\
\hline TMEn (kcal/kg) & & & 2,800 & & \\
\hline Crude protein $(\%)$ & & & 16.10 & & \\
\hline Ether extract $(\%)$ & & & 2.95 & & \\
\hline Crude fiber $(\%)$ & & & 3.40 & & \\
\hline $\mathrm{Ca}(\%)$ & & & 3.86 & & \\
\hline Available P (\%) & & & 0.50 & & \\
\hline Met+cys (\%) & & & 0.65 & & \\
\hline
\end{tabular}

${ }^{1} \mathrm{PP}=$ Persimmon peel PPE $=$ Persimmon peel extract.

${ }^{2}$ Mineral mixture provided following nutrients per kg of diet: Fe, $70 \mathrm{mg}$; Zn, $60 \mathrm{mg}$; Mn, $8 \mathrm{mg}$; Cu, $7.5 \mathrm{mg}$; I, $1 \mathrm{mg}$; Se, $0.2 \mathrm{mg}$; Co, $0.13 \mathrm{mg}$.

${ }^{3}$ Vitamin mixture provided following nutrients per kg of diet: vitamin A, 10,000 IU; vitamin $\mathrm{D}_{3}, 2,300 \mathrm{IU}$; vitamin E, $20 \mathrm{IU}$; vitamin $\mathrm{K}_{3}$, 2 mg; vitamin $\mathrm{B}_{1}, 2 \mathrm{mg}$; vitamin $\mathrm{B}_{2}, 5 \mathrm{mg}$; vitamin $\mathrm{B}_{6}, 3.5 \mathrm{mg}$; vitamin $\mathrm{B}_{12}, 0.02 \mathrm{mg}$; biotin, $0.12 \mathrm{mg}$; niacin, $30 \mathrm{mg}$; pantothenic acid, $10 \mathrm{mg}$; folic acid, $0.7 \mathrm{mg}$. 
replicate. Egg production rate and egg mass were recorded on a daily basis and determined on a replicate basis throughout the experiment. The mean egg weight was measured weekly, excluding cracked and soft-shell eggs. The eggs laid for the last three days of the experiment were used for analysis of egg qualities. Three eggs from each replicate were collected randomly. Eggshell thickness, strength, and color, albumen height, and yolk color were measured according to the method by Zheng et al. (2012); the Haugh unit was determined (Haugh, 1937). The collected eggs were maintained at room temperature (22 \pm $3^{\circ} \mathrm{C}$ ) for 7 or $14 \mathrm{~d}$ to observe the change in the Haugh unit.

After 6 wks of experimental feeding, 8 birds per treatment were sacrificed. The blood serum was centrifuged at $1,500 \mathrm{rpm}$ for $10 \mathrm{~min}$. During necropsy, the liver was immediately removed and weighed. The relative liver weight per $100 \mathrm{~g}$ body weight (BW) was calculated for each hen. Data were expressed as grams of organ per $100 \mathrm{~g}$ of BW. The serum and liver were preserved at $-20^{\circ} \mathrm{C}$ until further analysis. The activity of glutamic-oxaloacetic transaminase (GOT) and glutamic-pyruvic transaminase (GPT), as well as the total cholesterol concentration (totalC) and high-density lipoprotein-cholesterol (HDL-C) in the serum were measured according to the colorimetric method by using GOT-GPT assay kit (GOT-GPT assay kit, Asan Pharmaceutical, Hwaseong-si, Korea) and cholesterol diagnostic kit (Cholesterol E kit, HDL-cholesterol kit, Youngdong Medical Corporation). The superoxide dismutase activity (SOD) was determined by colorimetry according to the method by Stefan and Gudrun (1974).

The contents of each lipid fraction in the liver were determined using Iatroscan (MK-6 TLC/FID analyzer, Iatron Laboratories, Inc., Japan), which is a combination of silica-coated thin layer chromatography and flame ionization detector. The lipids were dissolved and were extracted using the method by Folch et al. (1957), and the liver lipid contents were detected using the method by An et al. (1997).

\section{Statistical analysis}

The main effects between the treated groups were subjected to ANOVA by using the general linear model of
SAS (SAS Institute, 2002). Significant differences at $\mathrm{p}<$ 0.05 were determined using Duncan's multiple range test (Duncan, 1955). Percentage data were transformed to arc sine percentages before square root percentages ANOVA was performed.

\section{RESULTS AND DISCUSSION}

The total tannin concentration of tannins in PPE and PP were $0.457 \pm 0.21 \%$ and $0.235 \pm 0.02 \%$, respectively. The effects of dietary PP and PPE on feed intake and egg production are shown in Table 2. The results indicated that egg production in the PP 0.5 group was higher than in the other groups $(\mathrm{p}<0.05)$. Conversely, egg production and mass of hens in the PPE 0.25 group were lower than that in the other groups $(\mathrm{p}<0.05)$. Feed intake and egg weight were not affected by the dietary treatments. The addition of $0.5 \%$ PP in the diet significantly increased egg production, whereas addition of $0.25 \%$ PPE resulted in a significant decrease in egg production and mass. It has been shown that fruits like persimmon have high tannin content, and it affects the acceleration of secretion of intestinal juice and intestinal contraction (Yu, 1976; Kitagawa and Glucina, 1984). Previous studies have shown that up to $2 \%$ tannin level reduces feed consumption and egg production (Armanious et al., 1973; Blakeslee and Wilson, 1979). In the present study, the tannin content in $0.25 \%$ PPE feed was similar to that in $0.5 \%$ PP feed $(0.11 \%)$. Thus, the decrease in egg production in the PPE 0.25 group may not have been affected by the tannin content. The improvement of egg production in the PP 0.15 group may mainly have been due to other nutrient compounds present in PP.

The effects of PP and PPE on egg quality are presented in Table 3. Eggshell color values of the PP and PPE treatment group hens were significantly higher than that of the control group hens $(\mathrm{p}<0.05)$. Eggshell strength and thickness, yolk color, and Haugh unit of eggs laid were not affected by the dietary level of PP or PPE.

The changes in Haugh units during storage are shown in Table 4. After $7 \mathrm{~d}$ of storage, the Haugh units in the groups fed diets containing PP and PPE were significantly higher than that of the control group $(\mathrm{p}<0.05)$. However, after $14 \mathrm{~d}$

Table 2. Effects of persimmon peel (PP) and persimmon peel ethanol extract (PPE) on feed intake and production performance in laying hens ${ }^{1}$

\begin{tabular}{lccccc}
\hline \multirow{2}{*}{ Items } & \multicolumn{5}{c}{ Treatment } \\
\cline { 2 - 6 } & CON & PP 0.15 & PP 0.5 & PPE 0.075 & PPE 0.25 \\
\hline Feed intake (g/d/bird) & $109.18 \pm 8.51$ & $109.43 \pm 12.09$ & $116.00 \pm 7.88$ & $105.12 \pm 4.00$ & $100.95 \pm 2.11$ \\
Egg production (\%) & $63.82 \pm 0.99^{\mathrm{b}}$ & $63.99 \pm 0.96^{\mathrm{b}}$ & $66.82 \pm 0.84^{\mathrm{a}}$ & $63.93 \pm 0.84^{\mathrm{b}}$ & $57.36 \pm 0.72^{\mathrm{c}}$ \\
Egg weight (g/egg) & $67.62 \pm 0.82$ & $67.24 \pm 0.29$ & $66.62 \pm 0.29$ & $67.02 \pm 0.32$ & $66.71 \pm 0.41$ \\
Egg mass (g/d/bird) & $43.09 \pm 0.77^{\mathrm{a}}$ & $43.06 \pm 0.72^{\mathrm{a}}$ & $44.53 \pm 0.58^{\mathrm{a}}$ & $42.85 \pm 0.58^{\mathrm{a}}$ & $38.26 \pm 0.49^{\mathrm{b}}$ \\
\hline
\end{tabular}

\footnotetext{
${ }^{1}$ Values are presented mean \pm SE (mean \pm SE of 4 groups, each group was composed of 3 cages, 2 hens per cage).
}

${ }^{\mathrm{a}-\mathrm{c}}$ Values with different superscript were significantly differ $(\mathrm{p}<0.05)$. 
Table 3. Effects of persimmon peel (PP) and persimmon peel ethanol extract (PPE) on egg quality in laying hens ${ }^{1}$

\begin{tabular}{lccccc}
\hline \multirow{2}{*}{ Items } & \multicolumn{5}{c}{ Treatment } \\
\cline { 2 - 6 } & \multicolumn{1}{c}{ CON } & PP 0.15 & PP 0.5 & PPE 0.075 & PPE 0.25 \\
\hline Eggshell color, unit & $26.69 \pm 0.87^{\mathrm{c}}$ & $33.80 \pm 0.87^{\mathrm{a}}$ & $31.77 \pm 1.22^{\mathrm{ab}}$ & $31.00 \pm 1.38^{\mathrm{ab}}$ & $28.60 \pm 1.30^{\mathrm{bc}}$ \\
Yolk color, Roche yolk color fan & $7.82 \pm 0.12^{\mathrm{ab}}$ & $7.53 \pm 0.13^{\mathrm{b}}$ & $7.86 \pm 0.10^{\mathrm{ab}}$ & $8.07 \pm 0.18^{\mathrm{a}}$ & $7.53 \pm 0.13^{\mathrm{b}}$ \\
Eggshell strength $\left(\mathrm{kg} / \mathrm{cm}^{2}\right)$ & $3.16 \pm 0.18$ & $3.23 \pm 0.15$ & $3.18 \pm 0.15$ & $3.05 \pm 0.14$ & $3.21 \pm 0.16$ \\
Eggshell thickness $(0.01 \mathrm{~mm})$ & $35.41 \pm 0.80$ & $34.97 \pm 0.66$ & $33.99 \pm 0.87$ & $33.87 \pm 0.78$ & $35.95 \pm 1.05$ \\
\hline
\end{tabular}

${ }^{1}$ Values are presented mean \pm SE (mean \pm SE of 4 groups, each group was composed of 3 cages, 2 hens per cage).

${ }^{\mathrm{a}-\mathrm{c}}$ Values with different superscript were significantly differ $(\mathrm{p}<0.05)$.

Table 4. Effects of persimmon peel (PP) and persimmon peel ethanol extract (PPE) on the change of Haugh unit in laying hens ${ }^{1}$

\begin{tabular}{lccccr}
\hline Items & \multicolumn{5}{c}{ Treatment } \\
\cline { 2 - 6 } & \multicolumn{1}{c}{ CON } & PP 0.15 & PP 0.5 & PPE 0.075 & PPE 0.25 \\
\hline Haugh unit (0 d) & $83.12 \pm 2.85$ & $89.48 \pm 3.37$ & $83.98 \pm 3.36$ & $86.80 \pm 2.50$ & $85.95 \pm 1.56$ \\
Haugh unit (7 d) & $68.43 \pm 1.92^{\mathrm{b}}$ & $81.55 \pm 3.67^{\mathrm{a}}$ & $78.70 \pm 2.55^{\mathrm{a}}$ & $82.58 \pm 3.43^{\mathrm{a}}$ & $81.56 \pm 2.27^{\mathrm{a}}$ \\
Haugh unit (14 d) & $72.12 \pm 2.26$ & $77.96 \pm 2.43$ & $77.08 \pm 1.74$ & $75.22 \pm 1.63$ & $74.36 \pm 1.90$ \\
\hline
\end{tabular}

${ }^{1}$ Values are presented mean \pm SE (mean \pm SE of 4 groups, each group was composed of 3 cages, 2 hens per cage).

${ }^{a, b}$ Values with different superscript were significantly differ $(\mathrm{p}<0.05)$.

of storage, no significant differences were observed among the groups. Ingram et al. (2008) found a high correlation between eggshell color and thickness. The same Authors reported that some egg quality traits such as shell strength, thickness, weight, and ultrastructure could be assessed by observing the eggshell color. However, there were no distinct links between eggshell color and egg weight, yolk color, and Haugh unit (Yang et al., 2009). No definitive conclusions have yet been reached on the correlation between eggshell color and internal quality of eggs. The Haugh unit tends to decrease with increased storage time (Williams, 1992; Tona et al., 2004; Hasan and Aylin, 2009). Albumen quality has been shown to increase by the addition of antioxidants such as vitamin $\mathrm{C}$, vitamin $\mathrm{E}$, and $\mathrm{Se}$ in laying hens diet (Keshavarz, 1996; Sahin et al., 2003). The significant difference in the Haugh units observed after $7 \mathrm{~d}$ of storage in the present study might be related to the antioxidants, vitamins, polyphenol, and tannins in PP.

No significant differences were found in the activities of serum GOT and GPT, or in the contents of total-C and HDL-C among the groups (Table 5). The SOD activity was also not affected by the dietary treatments. The GOT and GPT activity levels are indicative of liver damage in laying hens, and it can serve as a valuable tool for determining a safe inclusion rate for non-conventional feedstuff or feed additives (Goswami and Robblee, 1958; Lumeiji, 1997; Diaz et al., 2003). Thus, the administered levels of PP and PPE in this study appeared safe, and they may not exert adverse effects on the physiological status of the hens. It has been shown that the consumption of tannin prevents cardiovascular diseases (Tijburg et al., 1997; Santos-Buelga and Scalbert, 2000) and reduces serum cholesterol levels (Stensvold et al., 1992). Gorinstein et al. (1998) indicated that a persimmon-supplemented diet prevented total-C and low-density lipoprotein-cholesterol increase in rats fed a cholesterol diet, whereas persimmon in rats fed a basal diet without cholesterol did not significantly affect their blood cholesterol levels. Table 6 shows the liver weight and level of hepatic total-C, triacylglycerol, and phospholipid in laying hens. Liver weight was not affected by the dietary treatments. Hepatic total cholesterol levels of the PP 0.5 and PPE 0.25 group hens were lower than those of the other groups $(\mathrm{p}<0.05)$. Triacylglycerol levels in the PP 0.5 and PPE 0.25 groups were lower compared to that of the control group $(\mathrm{p}<0.05)$. The phospholipid levels in the PP and PPE treatment group hens were lower than those of the control

Table 5. Effects of persimmon peel (PP) and persimmon peel ethanol extract (PPE) on blood parameters and SOD activity in laying hens

\begin{tabular}{lrccrr}
\hline \multirow{2}{*}{ Items } & \multicolumn{5}{c}{ Treatment } \\
\cline { 2 - 6 } & \multicolumn{1}{c}{ CON } & PP 0.15 & PP 0.5 & PPE 0.075 & PPE 0.25 \\
\hline GOT (IU/L) & $222.36 \pm 7.95$ & $224.65 \pm 7.58$ & $214.51 \pm 6.66$ & $222.65 \pm 8.59$ & $214.02 \pm 6.23$ \\
GPT (IU/L) & $19.03 \pm 3.99$ & $21.90 \pm 3.75$ & $18.03 \pm 3.27$ & $20.97 \pm 4.38$ & $19.30 \pm 4.12$ \\
Total-C (mg/dl) & $135.26 \pm 6.78$ & $138.64 \pm 11.63$ & $148.68 \pm 12.54$ & $144.93 \pm 11.96$ & $133.97 \pm 5.99$ \\
HDL-C (mg/dl) & $8.01 \pm 2.25$ & $15.06 \pm 5.14$ & $8.95 \pm 1.57$ & $10.27 \pm 2.57$ & $18.77 \pm 2.58$ \\
SOD-like activity (\%) & $71.14 \pm 5.95$ & $63.56 \pm 5.84$ & $68.20 \pm 4.89$ & $71.18 \pm 3.84$ & $68.43 \pm 3.29$ \\
\hline
\end{tabular}

\footnotetext{
${ }^{1}$ Values are presented mean \pm SE (mean \pm SE of 4 groups, each group was composed of 3 cages, 2 hens per cage)
} 
Table 6. Effects of persimmon peel (PP) and persimmon peel ethanol extract (PPE) on lipid fractions of liver in laying hens ${ }^{1}$

\begin{tabular}{lccccc}
\hline \multirow{2}{*}{ Items } & \multicolumn{5}{c}{ Treatment } \\
\cline { 2 - 6 } & \multicolumn{1}{c}{ CON } & PP 0.15 & PP 0.5 & PPE 0.075 & PPE 0.25 \\
\hline Relative liver wt (g/100 g BW) & $1.25 \pm 0.10$ & $1.31 \pm 0.07$ & $1.38 \pm 0.10$ & $1.33 \pm 0.02$ & $1.34 \pm 0.08$ \\
Total cholesterol (mg/100 ml) & $2.87 \pm 0.07^{\mathrm{a}}$ & $2.85 \pm 0.07^{\mathrm{a}}$ & $2.63 \pm 0.02^{\mathrm{b}}$ & $2.72 \pm 0.05^{\mathrm{ab}}$ & $2.42 \pm 0.07^{\mathrm{c}}$ \\
Triacylglycerol $(\mathrm{mg} / 100 \mathrm{ml})$ & $5.94 \pm 1.55^{\mathrm{a}}$ & $5.73 \pm 0.07^{\mathrm{ab}}$ & $5.47 \pm 0.19^{\mathrm{bc}}$ & $5.57 \pm 0.09^{\mathrm{abc}}$ & $5.22 \pm 0.24^{\mathrm{c}}$ \\
Phospholipid $(\mathrm{mg} / 100 \mathrm{ml})$ & $26.82 \pm 0.73^{\mathrm{a}}$ & $24.43 \pm 0.88^{\mathrm{b}}$ & $23.20 \pm 0.57^{\mathrm{bc}}$ & $21.94 \pm 0.55^{\mathrm{cd}}$ & $20.74 \pm 0.77^{\mathrm{d}}$ \\
\hline
\end{tabular}

${ }^{1}$ Values are presented mean \pm SE (mean \pm SE of 4 groups, each group was composed of 3 cages, 2 hens per cage).

${ }^{\mathrm{a}-\mathrm{c}}$ Values with different superscript were significantly differ $(\mathrm{p}<0.05)$.

group hens $(\mathrm{p}<0.05)$. The results obtained in this study were consistent with previous findings of by Innami et al. (1998), who conducted experimental trials with rats fed dried persimmon leaf. The lowering of cholesterol in the liver is due to increased fecal excretion of bile acids and acceleration of cholesterol catabolism to a level that is greater than that of cholesterol synthesis in the liver. In the present study, diet containing $0.5 \%$ PP and $0.25 \%$ PPE were found to decrease hepatic cholesterol concentrations. This suggests that tannin is the principal effective component. Since polysaccharides and other polyphenol compounds are present in PP in addition to tannin, further studies are required to identify the exact components that are responsible for lowering hepatic cholesterol concentrations.

In conclusion, the inclusion of PP in the diets of laying hens is beneficial for improving production performance, egg quality in the late stage of egg production, and liver lipid concentrations.

Further studies using a larger number of hens and various PP and PPE contents are needed to clarify the exact mechanism involved in production performance.

\section{ACKNOWLEDGEMENT}

This work was supported by the grant of Rural Development Administration and Konkuk University, 2012.

\section{REFERENCES}

Ahn, H. S., T. I. Jeon, J. Y. Lee, S. G. Hwang, Y. H. Lim and D. K. Park. 2002. Antioxidative activity of persimmon and grape seed extract: in vitro and in vivo. Nutr. Res. 22:1265-1273.

Amarowicz, R., M. Naczk and F. Shahidi. 2000. Antioxidant activity of crude tannins of canola and rapeseed hulls. J. Am. Oil Chem. Soc. 77:957-961.

An, B. K., C. Banno, Z. S. Xia, K. Tanaka and S. Ohtani. 1997. Effects of dietary fat sources on lipid metabolism in growing chicks (Gallus domesticus). Comp. Biochem. Physiol. 116:119-125.

AOAC. 1995. Official methods of analysis. 16th edn. Association of Official Analytical Chemists, Washington, DC, USA.

Armanious, M. W., W. M. Britton and H. L. Fuller. 1973. Effect of methionine and choline on tannic acid and tannin toxicity in the laying hen. Poult. Sci. 52:2160-2168.
Blakeslee, J. A. and H. R. Wilson. 1979. Response of hens to various dietary levels of tannic acid. Poult. Sci. 58:255-256.

Diaz, G. J., L. P. Roldan and A. Cortes. 2003. Intoxication of Crotalaria pallida seeds to growing broiler chicks. Vet. Hum. Toxicol. 45:187-189.

Duncan, D. B. 1955. Multiple range and multiple $\mathrm{F}$ test. Biometrics 11:1-42.

Fry, J. L., G. M. Herrick, G. M. Prine and R. H. Harms. 1972. Effect of bird-resistant sorghums and tannic acid on yolk mottling. Poult. Sci. 51:1540-1543.

Folch, J., M. Lees and G. H. Sloane-Stanley. 1957. A simple method for the isolation and purification of total lipids from animal tissues. J. Biol. Chem. 226:497-509.

Gedir J. V., P. Sporns and R. J. Hudson. 2005. Extraction of condensed tannins from cervid feed and feces and quantification using a radial diffusion assay. J. Chem. Ecol. 31: 2761-2773.

Gorinstein, S., G. W. Kulasek, E. Bartnikowska, M. Leontowicz, M. Zemser, M. Morawiec and S. Trakhtenberg. 1998. The influence of persimmon peel and persimmon pulp on the lipid metabolism and antioxidant activity of rats fed cholesterol. J. Nutr. Biochem. 9:223-227.

Gorinstein, S., G. W. Kulasek, E. Bartnikowska, M. Leontowicz, M. Zemser, M. Morawiec and S. Trakhtenberg. 2000. The effects of diets, supplemented with either whole persimmon or phenol-free persimmon, on rats fed cholesterol. Food Chem. 70:303-308.

Gorinstein, S., Z. Zachwieja, M. Folta, H. Barton, J. Piotrowicz, M. Zemser, M. Weisz, S. Trakhtenberg and O. Martin-Belloso. 2001. Comparative contents of dietary fiber, total phonolics, and minerals in persimmons and apples. J. Agri. Food Chem. 49:952-957.

Goswami, M. N. D. and A. R. Robblee. 1958. Aspartic-glutamic transaminase activity in chick liver. Poult. Sci. 37:96-99.

Gross, J. 1987. Pigments in fruits (Ed. B. S. Schweiger). Academic Press, London, UK. pp. 87-245.

Hasan, A. and A. O. Aylin. 2009. Effects of storage time, temperature and hen age on egg quality in free-range layer hens. J. Anim. Vet. Adv. 8:1953-1958.

Haugh, R. R. 1937. The Haugh unit for measuring egg quality. US Egg Poult. Mag. 43:552-555, 572-573.

Ingram, D. R., L. F. Hatten III and K. D. Homan. 2008. A study on the relationship between eggshell color and eggshell quality in commercial broiler breeders. Int. J. Poult. Sci. 7:700-703.

Innami, S., K. Tabata, J. Shimizu, K. Kusunoki, H. Ishida, M. MAtsuguma, M. Wada, N. Sugiyama and M. Kondo. 1998. Dried green leaf powders of Jew's mellow (Corchorus), persimmon (Diosphyros kaki) and sweet potato (Ipomoea 
batatas poir) lower hepatic cholesterol concentration and increases fecal bile acid excretion in rats fed a cholesterol-free diet. Plant Foods Hum. Nutr. 52:55-65.

Kawase, M., N. Motohashi, K. Satoh, H. Sakagami, H. Nakashima, S. Tani, Y. Shirataki, T. Kurihara, G. Spengler, K. Wolfard and J. Molnar. 2003. Biological Activity of persimmon (Diospyros kaki) peel extracts. Phytother. Res. 17:495-500.

Keshavarz, K. 1996. The effect of different levels of vitamin C and cholecalciferol with adequate or marginal levels of dietary calcium on performance and eggshell quality of laying hens. Poult. Sci. 75:1227-1235.

Kitagawa, H. and P. G. Glucina. 1984. Persimmon culture in New Zealand. Science Information Publishing Center, Wellington, New Zealand. p. 74.

Lumeiji, J. T. 1997. Avian clinical biochemistry. In: Clinical Biochemistry of Domestic Animals, 5th Ed. (Ed. J. J. Kaneko, J. W. Harvey and M. L. Bruss). Academic Press, Oxford, UK. pp. 857-883.

Mallavadhani, U. V., A. K. Panda and Y. R. Rao. 1998 Pharmacology and chemotaxonomy of Diospyros. Phytochemistry 49:901-951.

NRC. 1994. Nutrient requirements of poultry. 9th ed. National Academy Press. Washington DC, USA.

Ortiz, L. T., C. Alzueta, J. Trevino and M. Castano. 1994. Effects of faba bean tannins on the growth and histological structure of the intestinal tract and liver of chicks and rats. Br. Poult. Sci. 35:743-754.

Parajuli, D., H. Kawakita, K. Inoue, K. Ohto and K. Kajiyama 2007. Persimmon peel gel for the selective recovery of gold. Hydrometallurgy 87:133-139.

Potter, D. K., H. L. Fuller and C. D. Blackshear. 1967. Effect of tannic acid on egg production and egg yolk mottling. Poult. Sci. 46:1508-1512.

Sahin, N., K. Sahin and M. Onderci. 2003. Vitamin E and selenium supplementation to alleviate cold-stressed associated deterioration in egg quality and egg yolk mineral concentrations of Japanese quails. Biol. Trace Elem. Res. 96:179-189.
Santos-Buelga, C. and A. Scalbert. 2000. Proanthocyanidins and tannin-like compounds - nature, occurrence, dietary intake and effects on nutrition and health. J. Sci. Food Agric. 80:10941117.

SAS Institute Inc. 2002. SAS/STAT user's guide: Statistics, Release 8.2 Edition. SAS Inst. Inc., Cary, North Carolina, USA.

Stefan, M. and M. Gudrun. 1974. Involvement of the superoxide anion radical in the autoxidation of pyrogallol and convenient assay for superoxide dismutase. Eur. J. Biochem. 47:469-474.

Stensvold, I., A. Tverdal, K. Solvoll and O. P. Foss. 1992. Tea consumption. relationship to cholesterol, blood pressure, and coronary and total mortality. Prevent. Med. 21:546-553.

Taira, S. 1996. Astringency in persimmon. In: Modern Methods of Plant Analysis (Ed. H. F. Linskens and J. F. Jackson). SpringerVerlag, Berlin, Heidelberg, pp. 97-110.

Tijburg, L. B. M., T. Mattern, J. D. Folts, U. M. Weisgerber and M. B. Katan. 1997. Tea flabonoids and cardiovascular diseases: a review. Crit. Rev. Food Sci. Nutr. 37:771-785.

Tona, K., O. Ongbesan, B. De Ketelaere, E. Deuypere and V. Bruggerman. 2004. Effects of age of broiler breeders and egg storage on egg quality, hatchability, chick quality, chick weight and chick posthatch growth to 42 days. J. Appl. Poult. Res. 13:10-18.

Williams, K. C. 1992. Some factors affecting albumen quallity with particular reference to Haugh unit score. World Poult. Sci. J. 48:5-16.

Yang, H. M., Z. Y. Wang and J. Lu. 2009. Study on the relationship between eggshell colors and egg quality as well as shell ultrastructure in Yangzhou chicken. Afr. J. Biotechnol. 8:28982902.

Yokozawa, T., T. Nakagawa and K. Kitani. 2002. Antioxidative activity of green tea polyphenol in cholesterol-fed rats. J. Agric. Food Chem. 50:3549-3552.

Yu, T. J. 1976. Food carte, pak myoung publishing Co., Seoul. pp. 129-132.

Zheng, L., S. T. Oh, J. Y. Jeon, B. H. Moon, H. S. Kwon, S. U. Lim, B. K. An and C. W. Kang. 2012. The dietary effects of fermented chlorella vulgaris $\left(\mathrm{CBT}^{\circledR}\right)$ on production performance, liver lipids and intestinal microflora in laying hens. Asian-Aust. J. Anim. Sci. 25:261-266. 